\title{
A New Function of Granulocyte Colony-stimulating Factor (G-CSF): Suppression of Cell Proliferation in Uterine Endometrial Carcinoma
}

\author{
Yayoi Fukuda ${ }^{1}$, Hitomi Nakamura ${ }^{1}$, Keiichi Kumasawa ${ }^{1,2,{ }^{*}}$, Tadashi Kimura ${ }^{1}$ \\ ${ }^{1}$ Department of Obstetrics and Gynecology, Osaka University Graduate School of Medicine, Osaka, Japan \\ ${ }^{2}$ Department of Obstetrics and Gynecology, Faculty of Medicine, The University of Tokyo, Tokyo, Japan \\ Email address: \\ yanpiyanyan@gmail.com(Y. Fukuda),hitomi@gyne.med.osaka-u.ac.jp(H. Nakamura),kumasawak-gyn@h.u-tokyo.ac.jp(K. Kumasawa), \\ tadashi@gyne.med.osaka-u.ac.jp(T.Kimura) \\ ${ }^{*}$ Corresponding author
}

\section{To cite this article:}

Yayoi Fukuda, Hitomi Nakamura, Keiichi Kumasawa, Tadashi Kimura. A New Function of Granulocyte Colony-stimulating Factor (G-CSF): Suppression of Cell Proliferation in Uterine Endometrial Carcinoma. Journal of Gynecology and Obstetrics. Vol. 7, No. 3, 2019 , pp. $92-99$. doi: $10.11648 /$ j.jgo.20190703.17

Received: March 27, 2019; Accepted: May 11, 2019; Published: June 12, 2019

\begin{abstract}
Granulocyte colony-stimulating factor (G-CSF) is cytokine which belongs to the family of colony-stimulating factors and recombinant human G-CSF has been widely used in clinical practice for treating patients with neutropenia for over 20 years. Recently, it has also seen use in assisted reproductive technology (ART) treatment based on the hypothesis that G-CSF might help the uterine endometrium proliferate and prepare for implantation. However, the risk of this treatment has not been fully assessed yet and there is a potential complication with its usage. It has been reported that G-CSF stimulates cell proliferation in hematopoietic cells and various other cell types, including cancer cells, suggesting that repeated local G-CSF administration into the uterine cavity might raises the risk of contracting uterine endometrial carcinoma. Based on this hypothesis, we assessed the effect of G-CSF on human uterine carcinoma cell proliferation, using cell lines. Our study showed that G-CSF administration produced dose-dependent suppression of proliferation of human uterine endometrial carcinoma cells through a G-CSF receptor-independent mechanism via a part of mitogen-activated protein kinase (MAPK) signaling pathway. While further studies will be needed to confirm G-CSFs efficacy in improving the outcomes of ART treatment, our data at least suggests that repeated G-CSF administration does not increase the risk of uterine endometrial carcinoma and may even lower it.
\end{abstract}

Keywords: Granulocyte Colony-stimulating Factor (G-CSF), Uterine Endometrial Carcinoma, Assisted Reproductive Technology (ART) Treatment

\section{Introduction}

Granulocyte colony-stimulating factor (G-CSF) is a cytokine that is named after its ability to induce the proliferation and differentiation of neutrophil precursors. Two types of the human glycoprotein are known, namely the 174- and 177-amino acid forms. The 174-amino acid-long form with a molecular weight of 19,600 is more potent than the 177-amino acid form; thus, the recombinant 174-amino acid form has been used in pharmaceutical applications [1-3]. G-CSF has been used worldwide for treating patients with neutropenia for over 2 decades.
G-CSF has long been studied for its effects on not only hematopoietic cells but also for its role in female reproduction. Among patients in assisted reproductive technology (ART) treatment, who received fresh embryo transfers, the pregnant women showed significantly higher serum G-CSF levels than those in the non-pregnant group [4]. Thus, it has been considered that G-CSF might be able to promote uterine endometrium proliferation and help in preparation for implantation. To improve the implantation rate, several clinical trials were conducted wherein G-CSF was administered by local uterine injection or subcutaneous injection in patients who received embryo transfers [5]. The 
efficacy of G-CSF administration in ART treatment has not been consistently demonstrated and further investigation is needed [5]. Bone and muscle pain are reported as general side effects of G-CSF administration. Moreover, the risks for myelodysplastic syndromes (MDS) and acute myelogenous leukemia (AML) can not be denied for long term G-CSF administration [6]. However, the risks of administering G-CSF during ART treatment have not been assessed yet.

Expression of the G-CSF receptor (G-CSF-R) is also reported in non-hematopoietic tissues such as cardiac muscle cells, vascular endothelial cells, and placental cells [7, 8]. However, the function of G-CSF-R is not fully understood yet. It has been reported that G-CSF induces cell proliferation via G-CSF-R in various cell types, including leukemia, bladder cancer, and glioma cells [9-11]. Regarding the female reproductive system, it was reported that G-CSF induced cell proliferation in normal chorionic cells [12]. However, a consensus has not been reached regarding the effect of G-CSF on cell proliferation in choriocarcinoma cells $[13,14]$ In normal uterine endometrium, a rat model of chemically induced endometrium thinning showed that G-CSF caused regeneration of the uterine endometrium in vivo [15]. However, no reports have described the effect of G-CSF on the proliferation of uterine endometrial carcinoma cells. During ART treatment, repeated G-CSF administration may be needed due to the low efficiency of ART treatment. One concern is that G-CSF-induced proliferation of the uterine endometrium may pose an increased risk for developing uterine endometrial carcinoma. In this study, we investigated the effect of G-CSF on cell proliferation using human uterine endometrial carcinoma cell lines.

\section{Materials and Methods}

\subsection{Cell Lines and Reagents}

Human uterine endometrial carcinoma cells (Ishikawa and HEC-1-A cells) and U937 cells (human myeloid cell line from a patient with histiocytic lymphoma) were kindly provided by Dr. Masato Nishida (Kasumigaura Medical Center, Ibaragi, Japan), Dr. Shinya Matsuzaki (Osaka University, Osaka, Japan), and Dr. Kenjiro Sawada (Osaka University) respectively. Recombinant G-CSF (Gran ${ }^{\circledR}$, Filgrastim) was kindly provided by Kyowa Hakko Kirin (Kyowa Hakko Kirin Co., Ltd., Tokyo, Japan).

\subsection{Cell Culture}

Ishikawa cells, HEC-1-A cells, and U937 cells were maintained in minimum essential medium (MEM, Nacalai Tesque, Inc., Kyoto, Japan), McCoy's 5A medium (Gibco®, Thermo Fisher Scientific K. K., Tokyo, Japan), and RPMI-1640 medium (Nacalai Tesque), respectively. All media were supplemented with $10 \%$ fetal bovine serum, penicillin $(100 \mathrm{IU} / \mathrm{ml})$, and streptomycin $(100 \mu \mathrm{g} / \mathrm{ml})$. The cells were maintained in a humidified incubator at $37 \quad \mathrm{C}$ in
$5 \% \mathrm{CO}_{2}$. Cells were seeded in 6-well plates at a density of 1 $\times 10^{5}$ cells/well in $2 \mathrm{ml}$ culture medium and allowed to attach for 24 hours. Twenty-four hours after plating cells, the each concentration of G-CSF was added every 24 hours at a final concentration of $0.5,5$, or $50 \mathrm{ng} / \mathrm{ml}$. Phosphate-buffered saline (PBS) was added as a negative (vehicle) control. The cells were counted using a hemocytometer at 48,72 , or 96 hours after plating.

\subsection{Semi-quantitative and Quantitative Reverse Transcription-polymerase Chain Reaction (RT-PCR) Experiments}

Total RNA was extracted using Trizol® (Invitrogen, CA, USA) and treated with DNase (TaKaRa Bio, Inc., Shiga, Japan). Single-stranded cDNA was synthesized from $3 \mu \mathrm{g}$ of total RNA using random primers and SuperScript III Reverse Transcriptase (Invitrogen), and sequential incubation at 70

$\mathrm{C}$ for $10 \mathrm{~min}, 25 \mathrm{C}$ for $5 \mathrm{~min}$, and $43 \mathrm{C}$ for $45 \mathrm{~min}$. All samples were reverse transcribed in a single batch and assayed with each individual primer set in the same PCR.

The primers for G-CSF receptor (G-CSF-R) was used as following based on previous studies [16-18]. Primers for glyceraldehyde-3-phosphate dehydrogenase (G3PDH) were purchased from Toyobo (Osaka, Japan). Primers pairs, progesterone receptor (PR), estrogen receptor (ER), and ER were designed using Primer Express version 2.0 software (Applied Biosystems, Foster City, CA, USA), and their sequences are shown in Table 1 . The negative control included in each reaction consisted of $\mathrm{H}_{2} \mathrm{O}$ substituted for cDNA.

PCR-amplification of G-CSF-R cDNA was performed using rTaq DNA polymerase (Toyobo). Amplification was performed in a 25- 1 reaction volume for 40 cycles (denaturation at $94^{\circ} \mathrm{C}$ for $30 \mathrm{sec}$, annealing at $58^{\circ} \mathrm{C}$ for $60 \mathrm{sec}$ and extension at $68^{\circ} \mathrm{C}$ for $60 \mathrm{sec}$ ) for G-CSF-R or 35 cycles (denaturation at $95^{\circ} \mathrm{C}$ for $30 \mathrm{sec}$, annealing at $60^{\circ} \mathrm{C}$ for $30 \mathrm{sec}$ and extension at $72^{\circ} \mathrm{C}$ for $75 \mathrm{sec}$ ) for G3PDH, using an Applied Biosystems 2720 thermal cycler. Five microlitres of each reaction mixture was electrophoresed on a $2 \%$ agarose gel, stained with ethidium bromide, and visualized by UV illumination.

For quantitative analysis of PR, ER, and ER mRNA expression, we employed reagents supplied with $2 \times$ SYBR Green PCR Master Mix (Applied Biosystems) and $0.5 \mu \mathrm{M}$ primers for all target RNAs. PCR amplification was performed in a StepOnePlus Real Time PCR System (Applied Biosystems) to allow amplicon quantification according to the manufacturer's instructions. Reaction products were analyzed by dissociation curve profile, and by $1 \%$ agarose gel electrophoresis. Assay optimization and validation experiments were performed as previously described [19]. Messenger RNA abundance data were normalized independently to -actin mRNA expression, and expressed in arbitrary units as a ratio of the mean value of the control group, where the mean of the control group was equal to 1 . 
Table 1. Primer sequences, product size and GenBank accession number for each target mRNA transcript.

\begin{tabular}{|c|c|c|c|}
\hline Target mRNA & Primer sequences & Product size (bp) & GenBank accession No. \\
\hline G-CSF-R & $\begin{array}{l}\text { 5'-AAGAGCCCCCTT ACCCACT ACACCA TCTT } \\
\text { 3'-TGCTGTGAGCTGGGTCTGGGACACTT }\end{array}$ & 340 & NM 172220 \\
\hline SOCS1 & $\begin{array}{l}\text { 5'-GTTTACATATACCCAGTATCTTTGCACAA } \\
\text { 3'-TATAAAATAGGATTCTGCACAGCAGAA }\end{array}$ & 90 & NM00003745 \\
\hline SOCS3 & $\begin{array}{l}\text { 5'-GTGGCCACTCTTCAGCATCTCT } \\
\text { 3'-GCATCGTACTGGTCCAGGAACT }\end{array}$ & 113 & NM004356 \\
\hline PR & $\begin{array}{l}\text { 5'-TGGGAGCTGTAAGGTCTTCTTTAAG } \\
\text { 3'-AACGATGCAGTCATTTCTTCCA }\end{array}$ & 82 & NM000926 \\
\hline $\mathrm{ER} \alpha$ & $\begin{array}{l}\text { 5'-CCA CCA ACC AgT gCA CCA TT } \\
\text { 3'-ggT CTT TTC gTA TCC CAC CTT TC }\end{array}$ & 108 & NM000125 \\
\hline ER $\beta$ & $\begin{array}{l}\text { 5'-AAGCACGTGTCCGCATTTTAG } \\
\text { 3'-TGCAAGAAGAGGCACAAAGGT }\end{array}$ & 113 & NM001437 \\
\hline
\end{tabular}

G-CSF-R; granulocyte colony stimulating factor receptor, SOCS; suppressor of cytokine signaling, PR; progesterone receptor, ER; estrogen receptor

\subsection{Western Blot Analysis}

Forty-eight hours after seeding cells (24 hours after administering G-CSF), the cells were washed twice with ice-cold PBS, and protein extracts were prepared by adding ice-cold lysis buffer [50 mM Hepes ( $\mathrm{pH} 7.5), 150 \mathrm{mM} \mathrm{NaCl}$, $1 \mathrm{mM}$ ethylenediaminetetraacetic acid (EDTA), $1 \mathrm{mM}$ dithiothreitol (DTT), 0.10\% NP-40, 10\% glycerol, $10 \mathrm{mM}$ -glycerophosphate, $1 \mathrm{mM} \mathrm{NaF}$, and $\left.0.1 \mathrm{mM} \mathrm{Na} \mathrm{VO}_{5}\right]$ supplemented with protease inhibitor cocktail (Nacalai Tesque, Inc., Kyoto, Japan). The lysates were centrifuged at $12,000 \times g$ for $5 \mathrm{~min}$ at $4 \mathrm{C}$, and the protein concentration was determined using a Protein Assay Kit (Bio-Rad, Hercules, CA, USA). Equal amounts of proteins were separated by $10 \%$ sodium dodecyl sulfate-polyacrylamide gel electrophoresis and transferred to nitrocellulose membranes. After blocking with 5\% non-fat dry milk, the membranes were incubated with antibodies against extracellular signal-regulated kinase (ERK) 1/2, phospho-ERK 1/2 (Thr202/Tyr204), stress-activated protein kinase/c-Jun N-terminal kinase (SAPK/JNK), and phospho-SAPK/JNK (Thr183/Tyr185) (Cell Signaling Technology, Tokyo, Japan) and then with a secondary horseradish peroxidase-conjugated IgG. The proteins were visualized with enhanced chemiluminescence (Nacalai Tesque, Inc.) according to the manufacturer's protocol. For quantitative analysis, the protein expression levels were assessed using ImageQuant TL software (GE Healthcare Bio-Sciences AB, Inc., Uppsala, Sweden).

\subsection{Statistical Analysis}

The data were analyzed using SigmaPlot ${ }^{\circledR}$ software, version 10.01 (Systat Software, Inc., San Jose, CA, USA). Data were analyzed by Student's $t$-test or the Wilcoxon ranksum test with the Shapiro-Wilk normality test, and differences with a $P$ value $<0.05$ were considered statistically significant.

\section{Results and Discussion}

\subsection{G-CSF-R Expression in Uterine Endometrial Carcinoma Cell Lines}

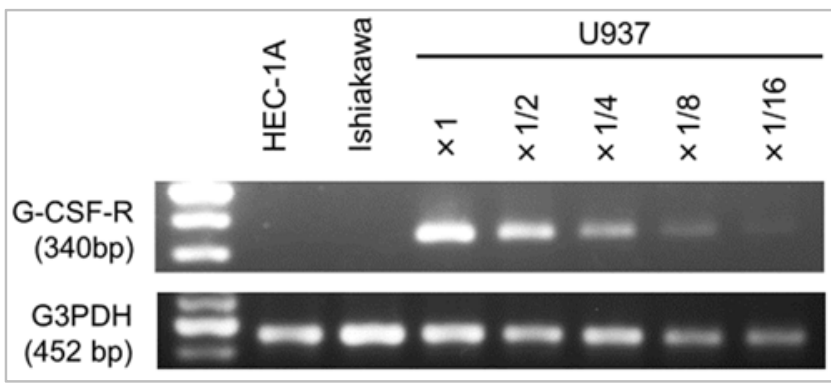

Figure 1. Expression of granulocyte colony stimulating factor receptor $(G-C S F-R) m R N A$.

It was previously reported that G-CSF induces cell proliferation among various cells via G-CSF-R [9-11, 20, 21]. G-CSF-R mRNA-expression levels were analyzed in HEC-1-A and Ishikawa human uterine endometrial carcinoma cells (Figure 1). U937 cells were used as a positive control. U937 cell cDNA was diluted 1:2, 1:4, 1:8, and 1:16, and amplified in parallel with cDNAs from HEC-1-A and Ishikawa cells. G-CSF-R mRNA was not detected in HEC-1-A and Ishikawa cells, although it was detected in U937 cells at the dilution (1:16), as shown in (Figure 1).

G-CSF-R mRNA-expression levels were assessed in HEC-1-A and Ishikawa cells by RT-PCR. U937 cells were used as a positive control for G-CSF-R mRNA expression. Glyceraldehyde-3-phosphate dehydrogenase (G3PDH) gene expression was detected as an internal control. The PCR products were resolved by $2 \%$ agarose gel electrophoresis and visualized after staining with ethidium bromide.

\subsection{Cell-proliferation Changes}

Although G-CSF-R mRNA was undetectable in HEC-1-A and Ishikawa cells, significantly fewer cells $(P<0.001$, Student's $t$-test) were observed at 48 hours after plating (24 hours after the addition of G-CSF), versus control cells. Compared with the control group, approximately $41 \%$ and $56 \%$ less HEC-1-A cells were observed in the 5 and $50 \mathrm{ng} / \mathrm{ml}$ groups, respectively $(\mathrm{n}=15$ each, Figure $2 A, 2 \mathrm{~B})$, and approximately $38 \%$ and $57 \%$ less Ishikawa cells were observed in the 5 and 50 $\mathrm{ng} / \mathrm{ml}$ groups, respectively ( $\mathrm{n}=12$ each, Figure $2 \mathrm{E}, 2 \mathrm{~F})$. No significant differences were found with the $0.5 \mathrm{ng} / \mathrm{ml}$ groups for either cell type (decreases of approximately $18 \%$ and $15 \%$ 
versus control-treated HEC-1-A and Ishikawa cells, respectively). At 72 hours after plating cells, the number of HEC-1-A cells significantly decreased in a dose-dependent manner (by approximately $27 \%, 43 \%$, and $56 \%$ in the $0.5,5$, and $50 \mathrm{ng} / \mathrm{ml}$ groups, respectively; all $P<0.001$, Student's $t$-test, Figure 2C), and the number of Ishikawa cells decreased by approximately $26 \%, 40 \%$, and $51 \%$ in the $0.5,5$, and $50 \mathrm{ng} / \mathrm{ml}$ groups, respectively $(P<0.05, P<0.005, P<0.001$, Student's $t$-test, Figure $2 \mathrm{G})$. Significant decreases were also observed in the $0.5,5$, and $50 \mathrm{ng} / \mathrm{ml}$ groups at 96 hours after plating, with both HEC-1-A cells (all $P<0.001$, Student's $t$-test, Figure 2D) and Ishikawa cells $(P<0.01, P<0.001$, and $P<0.001$, respectively, Student's $t$-test, Figure $2 \mathrm{H}$ ).

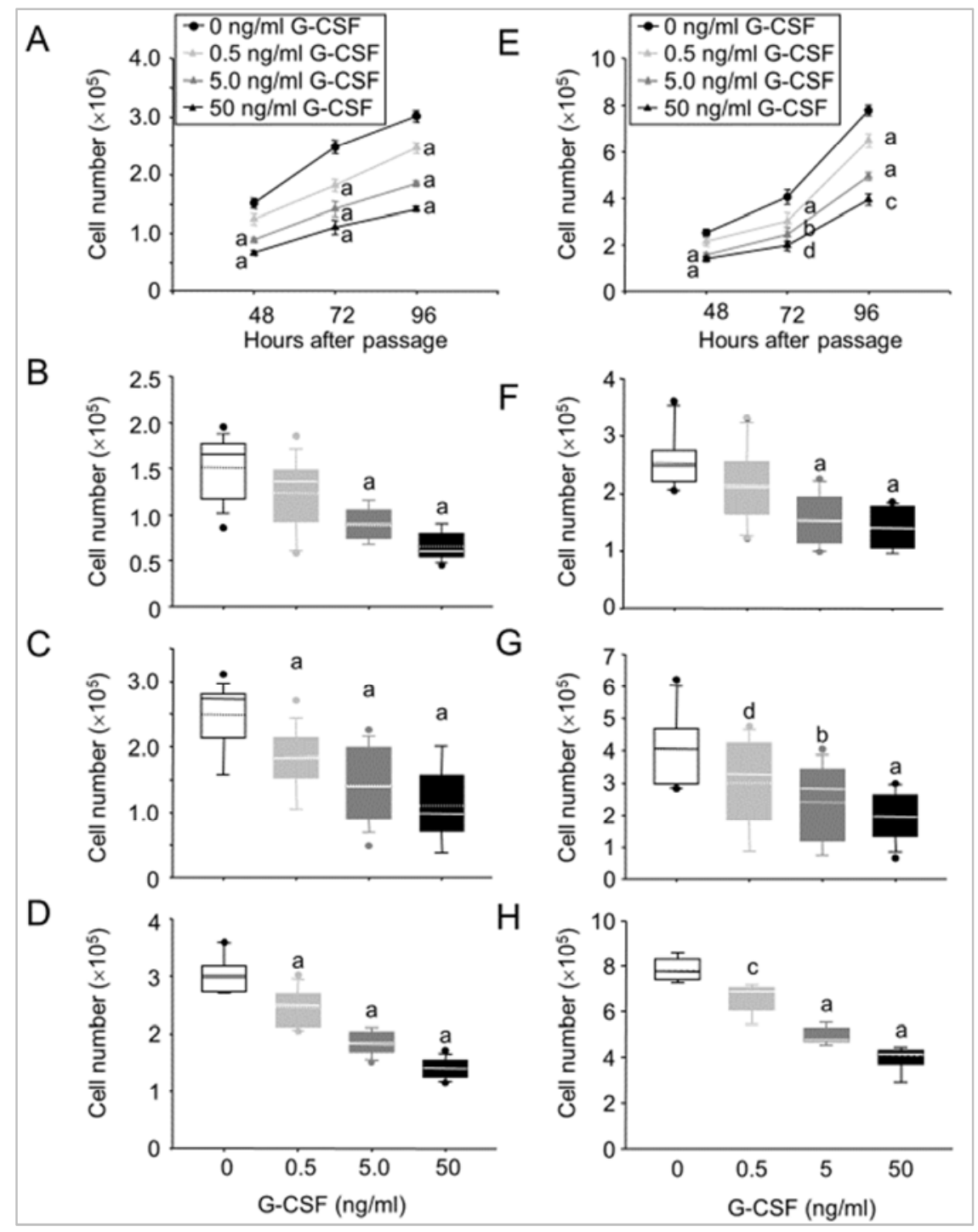

Figure 2. G-CSF suppressed HEC-1-A and Ishikawa cell proliferation.

The effects of G-CSF on cell counts (mean SEM) are shown graphically for HEC-1-A (A-D) and Ishikawa $(\mathrm{E}-\mathrm{H})$ cells at $48(\mathrm{~B}, \mathrm{~F}), 72(\mathrm{C}, \mathrm{G})$, and $96(\mathrm{D}, \mathrm{H})$ hours after the cells were seeded. The box plots show the numbers of HEC-1-A (B-D) and Ishikawa (F-H) cells observed at 48, 72, and 96 hours after seeding, where G-CSF was added 24 hours after seeding. The horizontal line within the box shows the median value, and the dotted line within the box shows the mean value. The data were evaluated using the Shapiro-Wilk normality test and Student's $t$-test $\left({ }^{\mathrm{a}} P<0.001,{ }^{\mathrm{b}} P<0.005,{ }^{\mathrm{c}} P<\right.$ $0.01,{ }^{d} P<0.05$, compared with the control group for the same cell line).

\subsection{Mitogen-activated Protein Kinase (MAPK) Signals}

To investigate whether G-CSF suppressed uterine endometrial carcinoma cell proliferation via MAPK signaling, JNK and ERK activities were assessed in cells at 48 hours after cell plating (24 hours after adding G-CSF; Figure 3 ). The phospho-JNK/JNK ratio decreased significantly in the $0.5 \mathrm{ng} / \mathrm{ml}$ groups for both HEC-1-A cells $(P<0.05$, Student's t-test, Figure 3A, 3B) and Ishikawa cells $(P<0.05$, Student's $t$-test, Figure 3E, 3F). The phospho-ERK/ERK ratio dose-dependently decreased in HEC-1-A cells $(P<0.01$ in the $0.5 \mathrm{ng} / \mathrm{ml}$ group, $P<0.001$ in the 5 and $50 \mathrm{ng} / \mathrm{ml}$ groups, Student's $t$-test, Figure 3C, 3D). In contrast, the 
phospho-ERK/ERK ratio dose-dependently increased in Ishikawa cells $(P<0.001$ in the 5 and $50 \mathrm{ng} / \mathrm{ml}$ groups, Student's $t$-test, Figure $3 \mathrm{G}, 3 \mathrm{H})$.

Although G-CSF dose-dependently decreased the proliferation of both HEC-1-A and Ishikawa cells (Figure 2), G-CSF showed an opposite effect in terms of the phospho-ERK/ERK ratio (Figure 3D, 3H). These findings suggest that changes in the phospho-ERK/ERK ratio did not directly contribute to the suppression of cell proliferation by G-CSF. The phospho-JNK/JNK ratio decreased in both lines. However, JNK signaling might not have been the main signal mediating suppressed cell proliferation by G-CSF, considering that a dose-dependent effect was not observed (Figure 3E, 3F). G-CSF is known to induce proliferation in various cell types via G-CSF-R, and different signal-transduction pathways can be induced depending on the different binding sites of G-CSF-R [21]. The Jak-Stat pathway is one signaling pathway that regulates cell proliferation by G-CSF via G-CSF-R [9-11]. We analyzed the effect of G-CSF on the mRNA-expression level of suppressor of cytokine signaling (SOCS)-3, which is a negative regulator of G-CSF-R and down-regulates G-CSF signaling [22]. However, G-CSF caused no significant difference in SOCS-3 expression in either cell lines (data not shown). Therefore, we hypothesized that different signaling pathways might regulate the suppression of cell proliferation in uterine endometrial carcinoma cells by G-CSF.

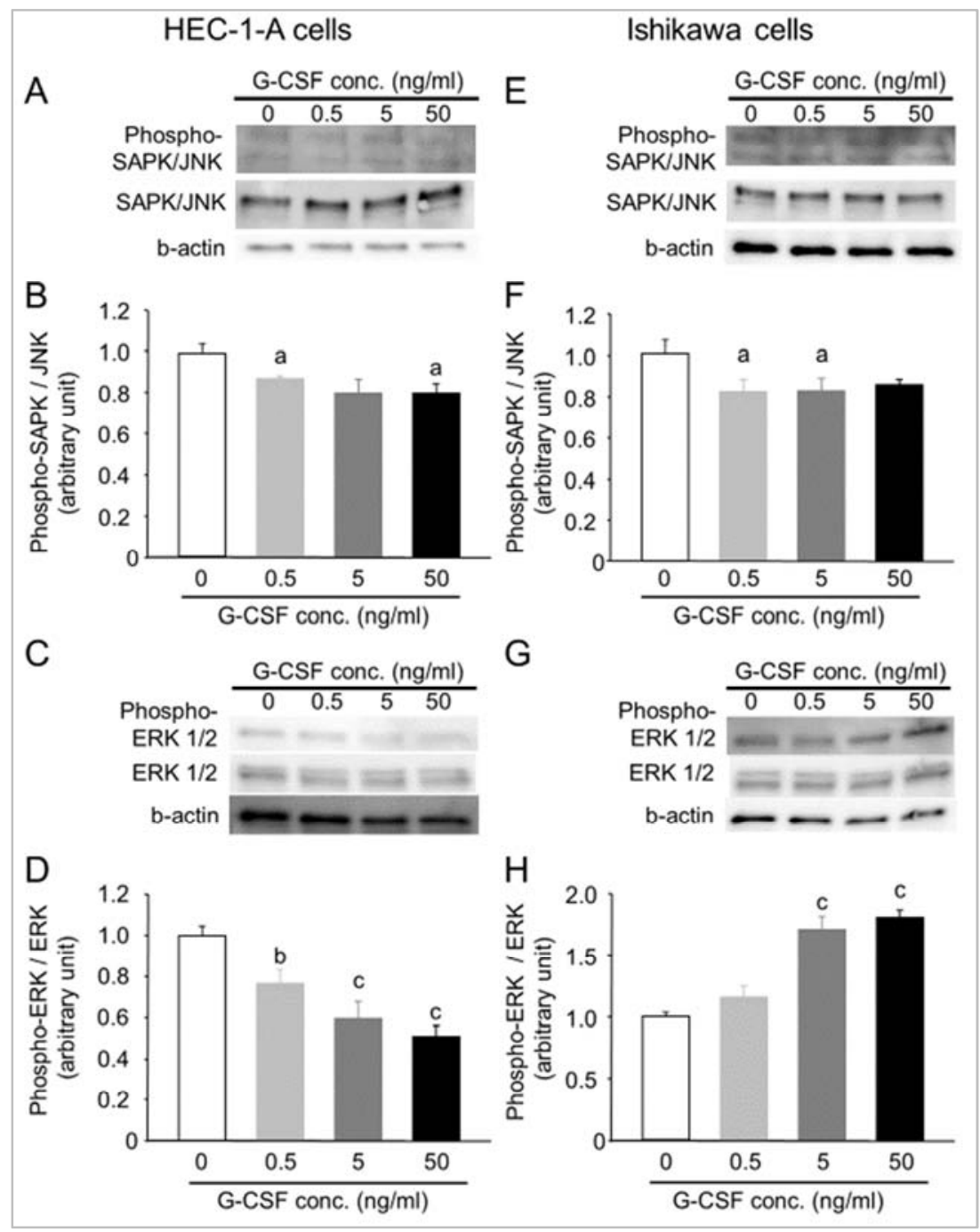

Figure 3. Analysis of mitogen-activated protein kinase (MAPK)-signaling pathway activation.

Analysis of stress-activated protein kinase/c-Jun $\mathrm{N}$-terminal kinase (SAPK/JNK) activation in $\operatorname{HEC}-1-\mathrm{A}(\mathrm{A}, \mathrm{B})$ and Ishikawa (E, F) cells by western blotting. Analysis of extracellular signal-regulated kinase (ERK) $1 / 2$ activation in HEC-1-A (C, D) and Ishikawa $(G, H)$ cells by western blotting. The bar graphs show fold-change relative to the medium-alone control group (mean

SEM). The data were evaluated using the Shapiro-Wilk normality test and Student's $t$-test $\left({ }^{\mathrm{a}} P<0.05,{ }^{\mathrm{b}} P<0.01,{ }^{\mathrm{c}} P<0.001\right)$.

\subsection{PR and ER $m R N A$ Appearance}

High-dose progestin therapy is a suitable and effective approach for treating atypical endometrial hyperplasia and early-stage uterine endometrial carcinoma for women who 
have strong desire to preserve their fertility. To investigate whether G-CSF administration affects expression of hormone receptors in human uterine endometrial carcinoma cells, quantitative analysis of PR, ER, and ER mRNA-expression levels was performed (Figure 4). G-CSF dose-dependently increased PR mRNA expression in Ishikawa cells (approximately 106\%, 115\%, and 144\% in the $0.5,5$, and $50 \mathrm{ng} / \mathrm{ml}$ groups, versus the control group, respectively, $P<0.05$ in the $50 \mathrm{ng} / \mathrm{ml}$ group, Mann-Whitney $\mathrm{U}$ test, Figure 4D), whereas PR mRNA expression was not detected in HEC-1-A cells (Figure 4A). It was reported previously that PR activated ERK in breast cancer cells [23,
24]. The dose-dependent increase in the phospho-ERK/ERK ratio by G-CSF in Ishikawa cells might be regulated via PR. ER mRNA-expression levels also tend to dose-dependently increase in Ishikawa cells (approximately 110\%, 112\%, and $141 \%$ in the $0.5,5$, and $50 \mathrm{ng} / \mathrm{ml}$ groups, respectively, $P<$ 0.001 in the $50 \mathrm{ng} / \mathrm{ml}$ group vs. control group, Student's $t$-test, Figure 4E) and in HEC-1-A cells (approximately 101\%, 112\%, and $137 \%$ in the $0.5,5$, and $50 \mathrm{ng} / \mathrm{ml}$ groups, versus the control group, respectively, Figure 4B). The mRNA-expression levels of ER in both cell lines did not show any significant difference in any group (Figure 4C, 4F).

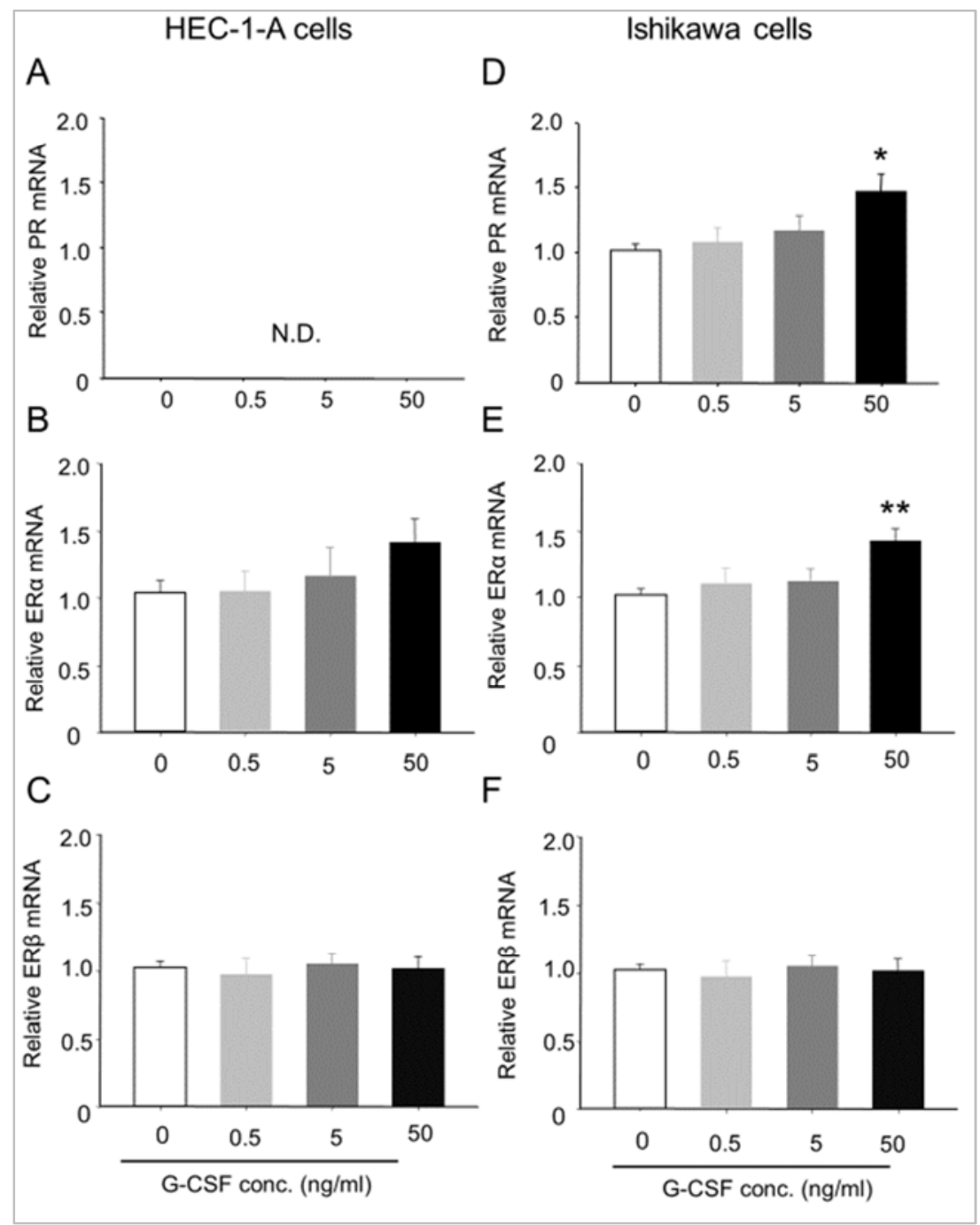

Figure 4. Effect of G-CSF on progesterone receptor (PR), estrogen receptor (ER), and ER mRNA-expression levels.

$\operatorname{PR}(\mathrm{A}, \mathrm{D}), \mathrm{ER} \alpha(\mathrm{B}, \mathrm{E})$ and $\operatorname{ER} \beta(\mathrm{C}, \mathrm{F})$ mRNA-expression levels in HEC-1-A (A-C) and Ishikawa (D-F) cells measured by qRT-PCR at 24 hours after adding G-CSF (48 hours after plating cells; $0,0.5,5$, and $50 \mathrm{ng} / \mathrm{ml} \mathrm{G-CSF}$ ). The data shown were normalized to b-actin expression and expressed as fold-changes relative to the medium-alone control group (mean SEM). The data were evaluated using the ShapiroWilk normality test, Mann-Whitney U test, and Student's $t$-test $\left({ }^{*} P<0.001\right.$, Mann-Whitney U test, ${ }^{* *} P<0.05$ Student's $t$-test).

G-CSF can induce cell proliferation in many normal cell types (including normal chorionic cells) and in cancer cells $[9,11]$. In contrast, the only report showing that G-CSF suppressed cell proliferation was performed with BeWo (culture condition: $2.5-10 \%$ serum) and JEG-3 (2.5\% serum) human choriocarcinoma cells (half-maximal effect of G-CSF observed at 30-50 ng/ml) [13] in agreement with the present report (however, Marino et al. showed that JEG-3 cell 
proliferation increased after administration of $1 \mathrm{~g} / \mathrm{ml}$ of G-CSF in culture medium containing $0.5 \%$ serum [14]). Only chorionic and uterine endometrium cells showed opposite effects on cell proliferation induced by G-CSF, when comparing normal and carcinoma cells. These observations raise the question as to whether cells in female reproductive system employ special mechanisms, resulting in the observed proliferation differences.

Normal chorionic and uterine endometrium cells can proliferate only to a certain degree, after which further growth is inhibited. During the menstrual cycle, endometrium proliferation is promoted by estrogen, and when progesterone is secreted from the corpus luteum after ovulation, proliferation of the uterine endometrium stops and then the endometrium is replaced by menstruation [25]. In contrast, atypical endometrial hyperplasia and uterine endometrial carcinoma are often identified by abnormally thick endometrium via ultrasonography [26]. Thinning of the endometrium during ART treatment has been reported to lower pregnancy rates [27]. However, pregnancy rates are also lower in women when the uterine endometrium is more than $15 \mathrm{~mm}$ thick [28]. Thus, for effective implantation, an appropriate thickness (not too thin or too thick) of the uterine endometrium is necessary. In clinical trials investigating ART treatment, G-CSF administration significantly increased the thickness of the uterine endometrium in patients with a thin endometrium [29], but did not affect the endometrial thickness in patients without thin endometrium [30]. However, in these clinical trials, the observation time was short and the risk of uterine endometrial cancer was not addressed.

It is known that progesterone (progestin) inhibits cell proliferation via $\mathrm{PR}$ in normal uterine endometrium and endometrial carcinoma cells, and many reports have shown that the process requires the participation of several key molecules [31]. However, the underlying mechanism is not fully explained yet.

\section{Conclusions}

In this study, we showed that G-CSF dose-dependently suppressed cell proliferation, independently of G-CSF-R. However, G-CSF might engage in crosstalk with granulocyte-macrophage colony-stimulating factor [32]. G-CSF-dependent suppression of cell proliferation in uterine endometrial carcinoma cells might be regulated by many other signals, including the MAPK pathway and hormonal receptors. Thus, further studies are required to understand the functional role (s) of G-CSF in uterine endometrial carcinoma cells.

The data generated in this study demonstrate that G-CSF dose-dependently suppressed human uterine endometrial carcinoma cell proliferation through a G-CSF-R-independent mechanism. There is insufficient evidence to recommend for or against G-CSF administered locally or systemically to improve outcome of ART treatment [5]. However, the present data suggest that G-CSF administration may not pose an increased risk for developing uterine endometrial carcinoma.

\section{Acknowledgements}

We thank Ms. Eriko Kamata (Osaka University) for providing technical assistance. This work was supported in part by the Japan Society for the Promotion of Science JSPS KAKENHI (grant numbers 16K11086 and 17K11232) from the Ministry of Education, Science, and Culture of Japan (Tokyo, Japan).

\section{Conflict of Interest}

The authors declare that they have no conflicts of interest.

\section{References}

[1] Metcalf, D. (1985). The granulocyte-macrophage colony-stimulating factors. Science 229, 16-22.

[2] Nagata, S. et al. (1986). Molecular cloning and expression of cDNA for human granulocyte colony-stimulating factor. Nature 319, 415-8.

[3] Souza, L. M. et al. (1986). Recombinant human granulocyte colony-stimulating factor: effects on normal and leukemic myeloid cells. Science 232, 61-5.

[4] Salmassi, A., Schmutzler, A. G., Schaefer, S., Koch, K., Hedderich, J., Jonat, W. and Mettler, L. (2005). Is granulocyte colony-stimulating factor level predictive for human IVF outcome? Hum Reprod 20, 2434-40.

[5] ASRM@asrm.org, P.C.o.t.A.S.f.R.M.E.a. and Medicine, P.C.o.t.A.S.f.R. (2018). The role of immunotherapy in in vitro fertilization: a guideline. Fertil Steril 110,387-400.

[6] Freedman, M. H. et al. (2000). Myelodysplasia syndrome and acute myeloid leukemia in patients with congenital neutropenia receiving G-CSF therapy. Blood 96, 429-36.

[7] Würfel, W. (2015). Treatment with granulocyte colony-stimulating factor in patients with repetitive implantation failures and/or recurrent spontaneous abortions. J Reprod Immunol 108, 123-35.

[8] Klocke, R., Kuhlmann, M. T., Scobioala, S., Schäbitz, W. R. and Nikol, S. (2008). Granulocyte colony-stimulating factor (G-CSF) for cardio- and cerebrovascular regenerative applications. Curr Med Chem 15, 968-77.

[9] Wang, J. et al. (2012). Granulocyte-colony stimulating factor promotes proliferation, migration and invasion in glioma cells. Cancer Biol Ther 13, 389-400.

[10] Chakraborty, A. and Guha, S. (2007). Granulocyte colony-stimulating factor/granulocyte colony-stimulating factor receptor biological axis promotes survival and growth of bladder cancer cells. Urology 69, 1210-5.

[11] Moon, H. W., Kim, T. Y., Oh, B. R., Hwang, S. M., Kwon, J., $\mathrm{Ku}$, J. L. and Lee, D. S. (2012). Effects of granulocyte-colony stimulating factor and the expression of its receptor on various malignant cells. Korean J Hematol 47, 219-24. 
[12] Duan, J. S. (1990). Production of granulocyte colony stimulating factor in decidual tissue and its significance in pregnancy. Osaka City Med J 36, 81-97.

[13] Vandermolen, D. T. and Gu, Y. (1996). Human endometrial expression of granulocyte colony-stimulating factor (G-CSF) and its receptor, stimulation of endometrial G-CSF production by interleukin-1 beta, and G-CSF inhibition of choriocarcinoma cell proliferation. Am J Reprod Immunol 36, 278-84.

[14] Marino, V. J. and Roguin, L. P. (2008). The granulocyte colony stimulating factor (G-CSF) activates Jak/STAT and MAPK pathways in a trophoblastic cell line. J Cell Biochem 103, 1512-23.

[15] Zhao, J., Tian, T., Zhang, Q., Wang, Y. and Li, Y. (2013). Use of granulocyte colony-stimulating factor for the treatment of thin endometrium in experimental rats. PLoS One 8, e82375.

[16] Gessler, P., Neu, S., Brockmann, Y. and Speer, C. P. (2000). Decreased mRNA expression of G-CSF receptor in cord blood neutrophils of term newborns: regulation of expression by G-CSF and TNF-alpha. Biol Neonate 77, 168-73.

[17] Zada, A. A. et al. (2006). Proteomic discovery of Max as a novel interacting partner of C/EBPalpha: a Myc/Max/Mad link. Leukemia 20, 2137-46.

[18] Slayton, W. B., Juul, S. E., Calhoun, D. A., Li, Y., Braylan, R. C. and Christensen, R. D. (1998). Hematopoiesis in the liver and marrow of human fetuses at 5 to 16 weeks postconception: quantitative assessment of macrophage and neutrophil populations. Pediatr Res 43, 774-82.

[19] Bonello, N., Jasper, M. J. and Norman, R. J. (2004). Periovulatory expression of intercellular adhesion molecule-1 in the rat ovary. Biol Reprod 71, 1384-90.

[20] Kendrick, T. S. and Bogoyevitch, M. A. (2007). Activation of mitogen-activated protein kinase pathways by the granulocyte colony-stimulating factor receptor: mechanisms and functional consequences. Front Biosci 12, 591-607.

[21] Layton, J. E. and Hall, N. E. (2006). The interaction of G-CSF with its receptor. Front Biosci 11, 3181-9.

[22] Hörtner, M., Nielsch, U., Mayr, L. M., Johnston, J. A., Heinrich, P. C. and Haan, S. (2002). Suppressor of cytokine signaling-3 is recruited to the activated granulocyte-colony stimulating factor receptor and modulates its signal transduction. J Immunol 169, 1219-27.
[23] Migliaccio, A. et al. (1998). Activation of the Src/p21ras/Erk pathway by progesterone receptor via cross-talk with estrogen receptor. EMBO J 17, 2008-18.

[24] Boonyaratanakornkit, V., Scott, M. P., Ribon, V., Sherman, L., Anderson, S. M., Maller, J. L., Miller, W. T. and Edwards, D. P. (2001). Progesterone receptor contains a proline-rich motif that directly interacts with $\mathrm{SH} 3$ domains and activates c-Src family tyrosine kinases. Mol Cell 8, 269-80.

[25] Cha, J., Sun, X. and Dey, S. K. (2012). Mechanisms of implantation: strategies for successful pregnancy. Nat Med 18, 1754-67.

[26] Colombo, N. et al. (2016). ESMO-ESGO-ESTRO Consensus Conference on Endometrial Cancer: diagnosis, treatment and follow-up. Ann Oncol 27, 16-41.

[27] El-Toukhy, T., Coomarasamy, A., Khairy, M., Sunkara, K., Seed, P., Khalaf, Y. and Braude, P. (2008). The relationship between endometrial thickness and outcome of medicated frozen embryo replacement cycles. Fertil Steril 89, 832-9.

[28] Weissman, A., Gotlieb, L. and Casper, R. F. (1999). The detrimental effect of increased endometrial thickness on implantation and pregnancy rates and outcome in an in vitro fertilization program. Fertil Steril 71, 147-9.

[29] Gleicher, N., Kim, A., Michaeli, T., Lee, H. J., Shohat-Tal, A., Lazzaroni, E. and Barad, D. H. (2013). A pilot cohort study of granulocyte colony-stimulating factor in the treatment of unresponsive thin endometrium resistant to standard therapies. Hum Reprod 28, $172-7$.

[30] Barad, D. H., Yu, Y., Kushnir, V. A., Shohat-Tal, A., Lazzaroni, E., Lee, H. J. and Gleicher, N. (2014). A randomized clinical trial of endometrial perfusion with granulocyte colony-stimulating factor in in vitro fertilization cycles: impact on endometrial thickness and clinical pregnancy rates. Fertil Steril 101, 710-5.

[31] Kim, J. J., Kurita, T. and Bulun, S. E. (2013). Progesterone action in endometrial cancer, endometriosis, uterine fibroids, and breast cancer. Endocr Rev 34, 130-62.

[32] Tanaka, T. and Umesaki, N. (2003). Regulation of the cellular subpopulation ratios of normal human endometrial stromal cells by macrophage colony-stimulating factor. Int J Mol Med $11,617-20$. 